\title{
Learning lessons from smallholder and community forest mosaics to support sustainable livelihoods in the Amazon
}

\begin{abstract}
Introduction
In the Peruvian and Ecuadoran Amazon, millions of hectares of tropical forests are owned, occupied or controlled by indigenous people or smallholders who depend on forest resources. These groups' forest management decisions are influenced by many factors, but one that is often poorly understood is the role of property rights. Property rights can be formal, informal or customary, shared or individual, contested or insecure. Together, these aspects affect forest use and market engagement.
\end{abstract}

Forest policies and management strategies should be tailored to smallholder and community needs based on a more complete understanding of the range of endogenous forest management systems that support local livelihoods, how and why these have changed over time, and how they link to forest products markets. This applied research, funded by the US Agency for International Development (USAID), is a two-year, cross-national comparative study designed to assist in the development of strategies to support sustainable forest management and conservation.

Why smallholder and community forests matter Increasingly, rural people in the Amazon and their forests are responding to, or being pressured by, market forces and frontier dynamics that encourage forest conversion. What are the factors driving this land use change, and what sustainable livelihood options are available that would benefit both forests and local people?

Forest frontiers are commonly home to a variety of actors with different interests in forests. Indigenous communities tend to have large, relatively intact forest areas held communally for subsistence purposes. Colonists are more likely to hold individual plots, which they convert from forest to agriculture or pasture. However, indigenous people also hold individual lands, convert forest to other uses, and sell timber. Similarly, many colonists keep forest reserves, reforest and sometimes join forces to manage forests in cooperatives and associations. In addition to local interests, other actors also play a role, such as timber, mining and petroleum enterprises. Their demands or formal rights overlay those of smallholders and indigenous people. Development actors have built new road networks and facilitated market access. Government regulators attempt to control behaviour and may shape it in unexpected ways, imposing new institutional arrangements over existing ones, pushing communities into informal markets or creating perverse incentives that lead to deforestation and degradation.

This study will analyse the diversity of actors and impacts of policy processes at the local landscape scale to illustrate the key drivers of local forest management decisions and forest

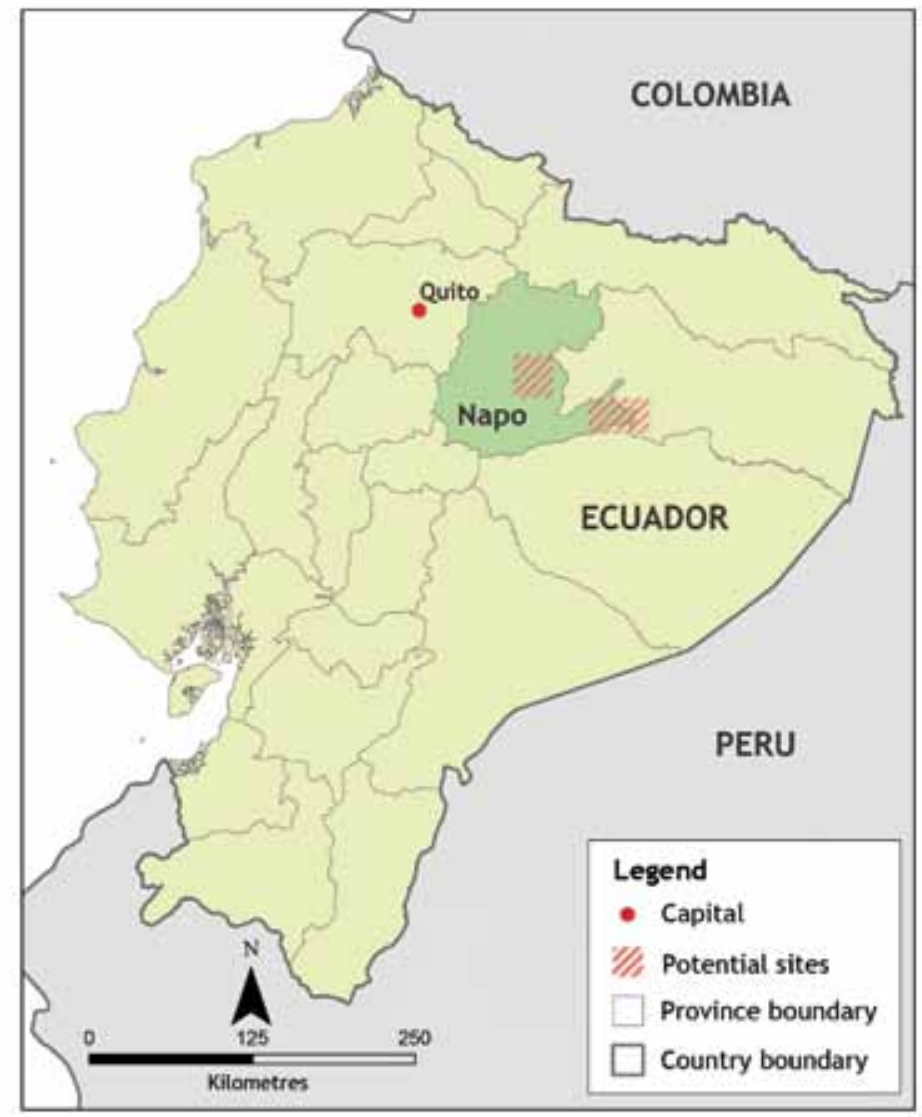

Research sites in Ecuador

transformation, and to identify lessons that will improve regional development, rural livelihoods and forest management.

Research in Ecuador will focus on the province of Napo, and in Peru research will take place in the departments of Huánuco and Ucayali. In both countries two field research sites - that cover areas of approximately 80,000 hectares each - will be selected to include a diversity of actors, forest uses and property rights regimes. In each country, sites will be selected to include both older and newer forest frontiers (see maps).

\section{Research objectives}

This research aims to identify the factors framing and constraining traditional and endogenous forest management systems of Amazonian smallholders and communities, in order to define improved programmes and strategies for supporting rural livelihoods, strengthening local governance institutions and promoting forest sustainability. 


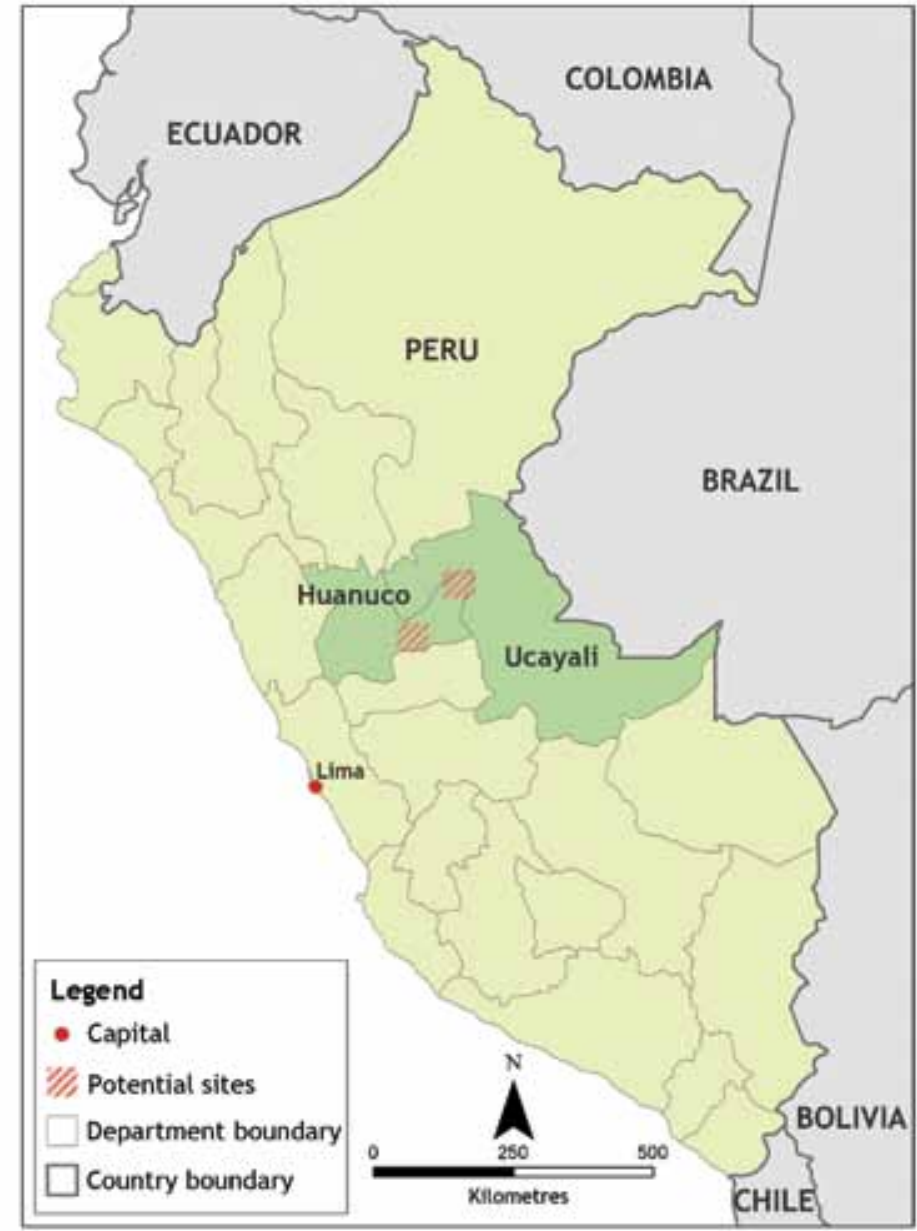

Research sites in Peru

The research initiative has four specific objectives:

- Define the mosaic of actors, formal and informal property rights regimes and forest management systems at the landscape scale in two research sites in each country;

- Examine the relations between observed mosaics of smallholder and community level forest management and drivers of land use change over time;

- Analyse the strategies and practices used by selected smallholder and community forest managers to link to important forest commodity markets and the importance of forest products in household livelihoods;

- Promote the design of appropriate models to support sustainable forest management and forest policies, laws and regulations, emphasizing on endogenous forestry practices and self-governance institutions.

\section{Project activities and outcomes}

This research will increase understanding of diverse smallholder and community forest management systems in Amazonian landscapes; analyze the effect of policy and regulatory frameworks; explore local linkages to forest product markets; and strengthen adaptive capacity of local resource users. The project has two components. The first will analyse land use change, property rights regimes and tenure security, and forest management systems of a variety of smallholder and indigenous actors at the landscape scale. It will explore the perceptions and plans of forest users, identify pressures and opportunities shaping traditional and endogenous management systems and analyse the role they play in the maintenance and conversion of forest cover. The second component will explore markets for specific forest products sold by smallholders and communities, analysing the strategies used to manage and market these products, the benefits derived from this trade, as well as how these systems are shaped by policies and regulatory frameworks.

\section{Role of partners}

CIFOR will coordinate the project, supervise research and support research conducted by local partners, particularly Grupo Faro in Ecuador and the Instituto del Bien Común in Peru. CIFOR will also coordinate cross-national training and exchange workshops. Research will take place in collaboration and consultation with USAID offices in Ecuador, the Costas y Bosques project; in Peru, the Environmental Management and Forest Governance Program and with consortiums supported by the Initiative for the Conservation of the Andean Amazon (ICAA) working in the selected regions to build synergies where interests overlap. The project will also engage with existing provincial and municipal level planning processes.

\section{Expected outputs and impacts}

The knowledge generated by this study will fill a gap in current research in the two countries. It will permit a greater understanding of factors affecting forest use and management behaviour of smallholders and communities, including land tenure arrangements, forest regulatory frameworks and market conditions and, hence, why local actors opt to maintain forest cover, degrade the forest, or deforest it through clearing.

The research seeks to contribute recommendations for policy and legal reforms and forest governance processes at national and subnational scales in the two countries, as well as for project interventions that support sustainable forestry. This analysis will also support the design of REDD+ programmes in each country and the region.

\section{USAID

